\title{
Smoking among a national sample of Aboriginal and Torres Strait Islander health service staff
}

l: n 2012-2013, the prevalence of daily smoking among Aboriginal and Torres Strait Islander adults was $42 \%$, although it is falling. ${ }^{1}$ For many years it has been suggested that the high smoking prevalence of Aboriginal health workers (AHWs) is a barrier to reducing smoking in the communities they serve., ${ }^{2,3}$ AHWs and other Aboriginal and Torres Strait Islander health service staff are role models and advocates for health in their communities, and there is evidence that AHWs who smoke have been less likely than those who do not to assist or promote smoking cessation. $^{2}$

The high prevalences of smoking previously reported among AHWs or other Aboriginal and Torres Strait Islander health service staff do not differ greatly from the high prevalences in their communities, but are based on small samples. ${ }^{3}$ Similarly high smoking prevalence among doctors has been reported in some developing countries, raising the same concerns about their roles in supporting cessation and as opinion leaders. ${ }^{4}$ In contrast, there has been a steady decline in smoking prevalence among doctors in most developed countries - in Australia, this fell from $27 \%$ in 1964 to $3 \%$ in 1997, much lower than in the general Australian population. ${ }^{5,6}$ MPH, FAFPHM, PhD ${ }^{4}$

Matthew Stevens $\mathrm{PhD}, \mathrm{BSc}$ (Hons)

Anke E van der Sterren $\mathrm{MPH}, \mathrm{MA}, \mathrm{BA}^{5}$

1 Menzies School of Health Research, Darwin, NT.

2 Aboriginal Health Service

Tasmanian Aboriginal

Centre, Hobart, TAS.

3 University of South Australia, Adelaide, SA

4 Aboriginal Health \& Medical Research Council, Sydney, NSW.

5 University of Melbourne, Melbourne, VIC.

david.thomas@ menzies.edu.au

doi: 10.5694/mjal4.01523
It has been asserted that smoking prevalence starts to fall earlier among doctors than among the general population as doctors are more likely to recognise the health consequences and change normative beliefs, and also become aware of the contradiction between their smoking and their role in improving health. ${ }^{7}$ The low smoking prevalence found among doctors is seen as an achievable future for the entire population. ${ }^{8}$

Here, we compare smoking prevalence, quitting activity and beliefs among a national sample of Aboriginal and Torres Strait Islander staff at Aboriginal community-controlled

Abstract

Objective: To examine smoking among Aboriginal and Torres Strait Islander staff of Aboriginal community-controlled health services (ACCHSs).

Design, setting and participants: The Talking About The Smokes (TATS) project surveyed 374 Aboriginal and Torres Strait Islander staff at a national sample of 31 ACCHSs, from April 2012 to October 2013. We made comparisons with adult participants in the 2008 National Aboriginal and Torres Strait Islander Social Survey (NATSISS) and with 1643 smokers in a community sample of 2522 Aboriginal and Torres Strait Islander people also surveyed in the TATS project.

Main outcome measures: Smoking status, smoking behaviour at work, quitting behaviour, attitudes and beliefs about smoking and quitting.

Results: Aboriginal and Torres Strait Islander ACCHS staff had a lower smoking prevalence than among all Aboriginal and Torres Strait Islander adults surveyed in the NATSISS (38\% v 49.8\%), but this difference was smaller when compared with only employed adults (38\% v 44.8\%). Staff smokers had higher odds than smokers in their communities of ever trying to quit (odds ratio [OR], 2.1; 95\% Cl, 1.1-3.7), of having often noticed antismoking advertising (OR, 2.8; 95\% Cl, 1.4-5.6), and of having used stopsmoking medications (OR, 3.0; 95\% Cl, 1.6-5.7), often with the support of their ACCHS. There was a significant association $(P<0.001)$ between the smoking status of Aboriginal and Torres Strait Islander staff and their confidence in talking to others about smoking and quitting; ex-smokers were most likely to report being confident. Most Aboriginal and Torres Strait Islander staff who smoked (74\%) agreed that being a non-smoker sets a good example to patients at their health service, and most did not smoke with patients or at work where patients could see them.

Conclusion: Smoking prevalence among Aboriginal and Torres Strait Islander ACCHS staff is only modestly lower than among other employed Aboriginal and Torres Strait Islander people. Given that ex-smokers feel more confident to help others quit than any other group, smoking cessation in ACCHS staff is a useful contributor to reducing community smoking rates.

health services (ACCHSs) and among members of their communities who smoke.

\section{Methods}

The Talking About The Smokes (TATS) project surveyed 2522 Aboriginal and Torres Strait Islander people in the communities served by 34 ACCHSs and one community in the Torres Strait between April 2012 and October 2013. At the same time, all staff at 31 of these ACCHSs were invited to complete a self-administered survey. Staff surveys were requested but not completed at four of the 35 project sites, owing to other local priorities.

The TATS project has been described elsewhere. ${ }^{9}$ Briefly, the 35 sites were selected based on the distribution of the Aboriginal and Torres Strait Islander population by state or territory and remoteness, using a quota sampling design. At each site, we aimed to survey 50 smokers (or exsmokers who had quit $\leqslant 12$ months previously) and 25 non-smokers from the community served by the ACCHS, with equal numbers in the smoking and non-smoking samples of men and women, and of those aged $18-34$ and $\geqslant 35$ years. In four large city sites and in the Torres Strait community, the sample size was doubled.

Staff surveys were paper-based at 20 ACCHSs and online at seven, with four offering both options. Surveys took 5-10 minutes to complete and included questions from the main community survey about smoking and quitting behaviour and attitudes, 
1 Comparison of smoking status of Aboriginal and Torres Strait Islander staff at ACCHSs with adults in the 2008 NATSISS

\begin{tabular}{|c|c|c|c|}
\hline \multirow[b]{3}{*}{ Status } & \multirow[b]{2}{*}{ ACCHS staff $(n=366)$} & \multicolumn{2}{|c|}{ NATSISS participants* } \\
\hline & & Employed $(n=3772)$ & Total $(n=7163)$ \\
\hline & Standardised \% (frequency) ${ }^{\dagger}$ & $\%(95 \% \mathrm{Cl})$ & $\%(95 \% \mathrm{Cl})$ \\
\hline Smoker & $38 \%(146)$ & $44.8 \%(42.1 \%-47.6 \%)$ & 49.8\% (47.8\%-52.5\%) \\
\hline Ex-smoker & $24 \%(88)$ & $22.3 \%(20.2 \%-24.4 \%)$ & 21.4\% (19.8\%-22.9\%) \\
\hline Never-smoker & $38 \%(132)$ & $32.9 \%(30.5 \%-35.5 \%)$ & $28.8 \%$ (26.9\%-30.7\%) \\
\hline
\end{tabular}

ACCHS = Aboriginal community-controlled health service. NATSISS = National Aboriginal and Torres Strait Islander Social Survey. *NATSISS results only include those aged $\geqslant 18$ years. $†$ Staff survey percentages are directly standardised to the age, sex and remoteness distribution of smokers in the NATSISS.

exposure to advertising, and use of cessation support. These were supplemented by questions about smoking at work, the respondent's role at the ACCHS, and smoking and cessation beliefs related to his or her role. The questions used in this article are listed in Appendix 1.

In contrast to the staff surveys, trained local interviewers completed the 30-60-minute survey of community members face to face using a computer tablet. A single survey of health service policy and activities was also completed by key informants at each site.

We compared the smoking status of Aboriginal and Torres Strait Islander staff with data from the 2008 National Aboriginal and Torres Strait Islander Social Survey (NATSISS). The NATSISS was a national, stratified, multistage, random, face-toface household survey with 7163 Aboriginal and Torres Strait Islander participants aged 18 years and over conducted by the Australian Bureau of Statistics from August 2008 to April 2009 , with an $82 \%$ response rate. ${ }^{10}$

We also compared the responses to questions about smoking and cessation practices and attitudes of Aboriginal and Torres Strait Islander staff who smoked with those of smokers in the community survey. We assessed differences in quitting and use of stop-smoking medications between staff who had active support from the health service to quit and those who did not.

The project was approved by three Aboriginal human research ethics committees (HRECs) and two HRECs with Aboriginal subcommittees: Aboriginal Health \&
Medical Research Council Ethics Committee, Sydney; Aboriginal Health Research Ethics Committee, Adelaide; Central Australian HREC, Alice Springs; HREC for the Northern Territory Department of Health and Menzies School of Health Research, Darwin; and the Western Australian Aboriginal Health Ethics Committee, Perth.

\section{Statistical analyses}

All comparisons of staff responses with the responses in the 2008 NATSISS or in the main community survey were directly standardised to the distribution of the age, sex and remoteness of either smokers or the total Aboriginal and Torres Strait Islander population in the 2008 NATSISS. As it not possible to estimate sampling error in non-probabilistic quota samples, we do not report confidence intervals around our prevalence estimates and only report percentages to the nearest integer.

The association between dichotomous variables within our samples was assessed using simple logistic regression to generate odds ratios (ORs) and $P$ values based on Wald tests, and using $\chi^{2}$ tests for other categorical variables. These results were analysed using Stata 13 (StataCorp) [SVY] commands to adjust for the sampling design (using site clusters in both the staff and community surveys, and age-sex quotas in the community survey as strata). NATSISS data were analysed using replicate and person weights as previously described. ${ }^{11}$

Except for attitude questions, where "don't know" responses were combined with "neither agree nor disagree", reported percentages and frequencies exclude participants not answering, answering "don't know", or for whom the question was not applicable. For the question about levels of confidence in talking to others about their smoking, we reported those who answered "don't know" but excluded 7\% who did not answer. Less than $5 \%$ of responses were excluded for all other questions analysed in this report, except for those in the staff survey about health service support of quit attempts (7\%), whether the last quit attempt was before or after being employed at the health service $(8 \%)$ and whether a quit attempt had been made in the past year $(13 \%)$.

\section{Results}

Surveys were completed by 645 staff at 31 ACCHSs, covering every state and territory as well as major cities and regional and remote areas (Appendix 2). As it was deemed impractical to precisely estimate total staff numbers, we have no precise response rate. However, it is unlikely to be above $50 \%$, as 215 surveys were completed at 17 services with up to 50 staff (mean, 12.6 surveys per ACCHS) and 430 at 14 services with more than 50 staff (mean, 30.7 per ACCHS).

Fifty-eight per cent of respondents (374/641) were Aboriginal or Torres Strait Islander people (Appendix 2). Of the Aboriginal and Torres Strait Islander staff, 76\% (286/374) were women, $48 \%$ (173/362) had been at the ACCHS longer than 2 years, $88 \%$ (319/362) worked full-time, $49 \%$ (181/367) were AHWs or community workers, 5\% (18/367) were doctors or nurses, $25 \%$ (92/367) were in other roles with direct client contact, $21 \%$ (76/367) had no contact with clients, and $17 \%(63 / 368)$ were in managerial roles.

Of the Aboriginal and Torres Strait Islander staff, 146 were smokers. None of those who smoked said they did so indoors at work, and 13\% (19/145) said they did not smoke at work. Most $(57 \%, 83 / 145)$ said they smoked outside the health service boundary or fence. In the past month, $41 \%$ (59/145) had smoked where ACCHS clients could see them. While 77\% (111/145) 
had smoked with co-workers during work hours in the past month, only $28 \%(40 / 145)$ had smoked with clients of the ACCHS. All ACCHSs had a smoke-free policy or rules. Most Aboriginal and Torres Strait Islander staff who smoked $(74 \%, 107 / 144)$ agreed that being a non-smoker sets a good example to patients at their health service.

\section{Comparison of Aboriginal and Torres Strait Islander staff with NATSISS participants}

Compared with all Aboriginal and Torres Strait Islander adults in the 2008 NATSISS, a lower standardised proportion of Aboriginal and Torres Strait Islander ACCHS staff smoked (38\% v 49.8\%), with more having never smoked and a similar proportion of ex-smokers (Box 1). The difference in the proportion of smokers was smaller when ACCHS staff were compared only with employed adults in the NATSISS ( $38 \%$ v $44.8 \%$ ). Staff who had ever smoked were more likely than their NATSISS counterparts to have successfully quit (38\% [88/234] v 30.1\% [95\% CI, 28.0\%-32.1\%]). Most of the staff ex-smokers $(62 \%, 50 / 81)$ had quit before they started working at the health service.

\section{Comparison of Aboriginal and Torres Strait Islander staff with community members}

A greater standardised proportion of Aboriginal and Torres Strait Islander smokers among the staff than among other community members had ever made a quit attempt (83\% [118/144] v 70\% [1143/1631]; OR, 2.1 [95\% CI, 1.1-3.7]; $P=0.02)$. However, the difference in the proportion of smokers who had made a quit attempt in the past year was not statistically significant (staff v community, 58\% [67/127] v 50\% [796/1609]; OR, 1.4 [95\% CI, 0.81-2.4]; $P=0.24$ ).

There were significant differences in how many of the respondent's five closest family or friends smoked, with staff smokers having lower odds than community smokers of reporting all five were smokers $(\mathrm{OR}$, $0.56 ; 95 \%$ CI, 0.34-0.94; $P=0.03$ ). Staff who smoked had significantly greater odds of having often or very often noticed advertising about the dangers

2 Comparison of smoking and cessation practices of smokers among Aboriginal and Torres Strait Islander ACCHS staff and community members*

\begin{tabular}{|c|c|c|c|}
\hline Practice & $\begin{array}{l}\text { ACCHS staff, } \\
\% \text { (frequency) }\end{array}$ & $\begin{array}{l}\text { Community members, } \\
\% \text { (frequency) }\end{array}$ & $P$ \\
\hline Smoking banned inside home & & & 0.19 \\
\hline Total ban & $64 \%(87)$ & $56 \%(908)$ & \\
\hline Partial ban & $22 \%(40)$ & $22 \%(359)$ & \\
\hline No ban & $14 \%(17)$ & $22 \%(361)$ & \\
\hline Number of five closest family or friends who smoke & & & 0.004 \\
\hline None & $7 \%(14)$ & $7 \%(120)$ & \\
\hline One & $8 \%(14)$ & $7 \%(119)$ & \\
\hline Two & $10 \%(21)$ & $15 \%(243)$ & \\
\hline Three & $35 \%(31)$ & $17 \%(273)$ & \\
\hline Four & $12 \%(23)$ & $12 \%(204)$ & \\
\hline Five & $28 \%(43)$ & $41 \%(649)$ & \\
\hline Noticed anti-smoking advertising in past 6 months & & & $<0.001$ \\
\hline Often or very often & $70 \%(116)$ & $45 \%(730)$ & \\
\hline Sometimes & $30 \%(28)$ & $34 \%(535)$ & \\
\hline Never or almost never & $1 \%(2)$ & $21 \%(341)$ & \\
\hline $\begin{array}{l}\text { Smokers who have ever made a quit attempt and have } \\
\text { used NRT or stop-smoking medications }\end{array}$ & 120 & 1155 & \\
\hline Any NRT or medications & $69 \%(71)$ & $43 \%(505)$ & 0.001 \\
\hline NRT patch & $54 \%(48)$ & $30 \%(362)$ & 0.003 \\
\hline NRT gum & $14 \%(21)$ & $13 \%(152)$ & 0.77 \\
\hline NRT lozenges & $5 \%(6)$ & $4 \%(42)$ & 0.67 \\
\hline NRT tablets & $5 \%(7)$ & $2 \%(18)$ & 0.03 \\
\hline Varenicline & $49 \%(38)$ & $13 \%(167)$ & $<0.001$ \\
\hline Bupropion & $9 \%(12)$ & $1 \%(17)$ & $<0.001$ \\
\hline
\end{tabular}

ACCHS = Aboriginal community-controlled health service. NRT = nicotine replacement therapy. * Results for the baseline sample of Aboriginal and Torres Strait Islander ACCHS staff smokers $(n=146)$ and community smokers $(n=1643)$ in the Talking About The Smokes project, April 2012 - October 2013. Percentages and frequencies exclude those who did not answer or answered "don't know". Percentages are directly standardised to the age, sex and remoteness distribution of smokers in the 2008 National Aboriginal and Torres Strait Islander Social Survey.

of smoking or that encouraged quitting in the past 6 months, compared with other community members who smoked (OR, 2.8; 95\% CI, 1.4-5.6; $P=0.004)($ Box 2).

Compared with community smokers, a significantly higher proportion of Aboriginal and Torres Strait Islander staff smokers who had ever made a quit attempt had used nicotine replacement therapy (NRT) or other stop-smoking medications, (OR, 3.0; 95\% CI, 1.6-5.7; $P=0.001$ ). Significantly higher proportions of staff reported use of NRT patches (OR, 2.8; 95\% CI, 1.5-5.2; $P=0.003$ ), NRT tablets (OR, 3.3; 95\% CI, 1.2-9.7; $P=0.03)$, varenicline (OR, 6.1; 95\% CI, 2.9-12.8; $P<0.001)$ and bupropion (OR, 6.6; 95\% CI, 2.5-17.2; $P<0.001$ ) (Box 2).

Nearly half of the staff smokers who had made a quit attempt $(47 \%, 52 / 111)$ had at least one of these attempts actively supported by the health service, most commonly through an information session for staff $(n=20)$ or access to free or subsidised NRT $(n=19)$. A higher proportion of staff who had health service support in their quit attempts, compared with those who did not, had ever used NRT or other stop-smoking medications (79\% [41/52] v 46\% [27/59]; OR, 4.4; 95\% CI, 1.9-10.4; $P=0.001$ ). However, staff from health services that reported providing additional cessation support for staff did not have significantly greater odds of making a quit attempt in the past year than those whose service did not $(56 \%$ [46/82] v 47\%, [21/45]; OR, 1.5 ; $95 \%$ CI, 0.65-3.3), although statistical power to detect a significant effect was low.

There were significant differences between staff smokers and community smokers in how much they 
3 Comparison of smoking and cessation attitudes of smokers among Aboriginal and Torres Strait Islander ACCHS staff and community members*

\begin{tabular}{|c|c|c|c|}
\hline Attitude & $\begin{array}{l}\text { ACCHS staff, } \\
\% \text { (frequency) }\end{array}$ & $\begin{array}{l}\text { Community } \\
\text { members, \% } \\
\text { (frequency) }\end{array}$ & $P$ \\
\hline $\begin{array}{l}\text { How much do you think you would benefit from better health and other } \\
\text { things if you were to quit smoking permanently in the next } 6 \text { months? }\end{array}$ & & & 0.03 \\
\hline Very much or extremely & $75 \%(113)$ & $61 \%(988)$ & \\
\hline Moderately & $20 \%(20)$ & $21 \%(323)$ & \\
\hline Slightly or not at all & $5 \%(6)$ & $18 \%(293)$ & \\
\hline $\begin{array}{l}\text { Smoking is not very risky when you think about all the other things that } \\
\text { people do }\end{array}$ & & & 0.19 \\
\hline Agree & $30 \%(36)$ & $46 \%(731)$ & \\
\hline Neither or don't know & $24 \%(32)$ & $17 \%(282)$ & \\
\hline Disagree & $46 \%(78)$ & $37 \%(621)$ & \\
\hline Being a non-smoker sets a good example to children & & & 0.52 \\
\hline Agree & $87 \%(135)$ & $91 \%(1482)$ & \\
\hline Neither or don't know & $4 \%(8)$ & $4 \%(75)$ & \\
\hline Disagree & $9 \%(3)$ & $5 \%(77)$ & \\
\hline Cigarette smoke is dangerous to non-smokers & & & 0.86 \\
\hline Agree & $93 \%(131)$ & $91 \%(1489)$ & \\
\hline Neither or don't know & $5 \%(13)$ & $6 \%(99)$ & \\
\hline Disagree & $2 \%(2)$ & $3 \%(46)$ & \\
\hline \multicolumn{4}{|c|}{$\begin{array}{l}\text { ACCHS = Aboriginal community-controlled health service. * Results for the baseline sample of Aboriginal and Torres Strait } \\
\text { Islander ACCHS staff smokers }(n=146) \text { and community smokers }(n=1643) \text { in the Talking About The Smokes project, April } 2012 \\
\text { - October 2013. Percentages and frequencies exclude those who did not answer (all questions) or answered "don't know" (first } \\
\text { question). Percentages are directly standardised to the age, sex and remoteness distribution of smokers in the } 2008 \text { National } \\
\text { Aboriginal and Torres Strait Islander Social Survey. }\end{array}$} \\
\hline
\end{tabular}

believed they would benefit if they were to quit smoking in the next 6 months $(P=0.03)$ (Box 3); staff had non-significantly greater odds of reporting they would benefit very much or extremely (OR, 1.95; 95\% CI, 0.92-4.2; $P=0.08)$. Smokers' riskminimising beliefs and beliefs about the dangers of second-hand smoke were similar among staff and other community members (Box 3). Most staff smokers $(58 \%, 85 / 146)$ agreed that staff and managers of the health service disapproved of smoking, with only $12 \%$ (18/146) disagreeing with this.

For Aboriginal and Torres Strait Islander staff who had direct contact with ACCHS clients, there was a significant association $(P<0.001)$ between their smoking status and whether they felt confident talking to others about smoking and quitting (Box 4). Ex-smokers were significantly more likely than smokers to report being very much or extremely confident (OR, 4.3; 95\% CI, 2.2-8.3; $P<0.001)$.

\section{Discussion}

Our results suggest that Aboriginal and Torres Strait Islander staff of ACCHSs have a lower smoking prevalence than other Aboriginal and Torres Strait Islander people.
However, our estimate of staff smoking may be falsely low, as our response rate was not high and smokers may have been less likely to complete our survey.

Our national estimate of staff smoking prevalence was at the lower end of previous smaller local and regional studies, and much lower than the largest previous study $(51 \%, n=85)$, which also reported the highest (but still a modest) response rate of $63 \% ., 12$ However, these studies concentrated on AHWs (variously defined) rather than all Aboriginal and Torres Strait Islander staff. In spite of the supportive environment at the ACCHSs, Aboriginal and Torres Strait Islander staff in our survey were still much more likely to smoke than either Australian doctors or other health professionals in similar countries. ${ }^{6,13}$ As in previous research with AHWs, and with other health professionals in other settings, we found that staff who smoked were less confident in talking about quitting. This remains a concern and a rationale for assisting Aboriginal and Torres Strait Islander smokers to quit, and may support preferential employment of non-smokers. ${ }^{5,14}$

The lower smoking prevalence among Aboriginal and Torres Strait Islander staff of ACCHSs was similar to the lower smoking prevalence among other employed Aboriginal and Torres Strait Islander people surveyed in the NATSISS, and was mainly due to more staff having never smoked (rather than more being ex-smokers).

Most of the ACCHS staff who still smoked agreed that being a nonsmoker sets a good example to patients. Fewer Aboriginal and Torres Strait Islander staff reported smoking with patients than with co-workers

4 Confidence in talking with others about smoking and quitting among Aboriginal and Torres Strait Islander staff with client contact, by smoking status*

\begin{tabular}{lcccc} 
Confident in talking about smoking and quitting & $\begin{array}{c}\text { Smokers } \\
(n=103)\end{array}$ & $\begin{array}{c}\text { Ex-smokers } \\
(n=65)\end{array}$ & $\begin{array}{c}\text { Never-smokers } \\
(n=97)\end{array}$ & $\begin{array}{c}\text { Total } \\
(n=265)\end{array}$ \\
\hline Very much or extremely & $27 \%(28)$ & $62 \%(40)$ & $37 \%(36)$ & $39 \%(104)$ \\
Moderately & $25 \%(26)$ & $26 \%(17)$ & $30 \%(29)$ & $27 \%(72)$ \\
Slightly or not at all & $38 \%(39)$ & $6 \%(4)$ & $27 \%(26)$ & $26 \%(69)$ \\
Don't know & $10 \%(10)$ & $6 \%(4)$ & $6 \%(6)$ & $8 \%(20)$ \\
\hline * Data are \% (frequency) and exclude those not answering. $\chi^{2}$ test of association, $P<0.001$. & &
\end{tabular}


at work, and most did not smoke where they could be seen by patients, suggesting they accept this responsibility as a role model. In contrast, research conducted in 2009-2010 found AHWs reported that patients liked them smoking with them, facilitating connection and patients opening up. ${ }^{15}$ The same study reported that an organisational culture that supported smoking undermined quitting. However, we found that smoking was now usually not perceived as acceptable in ACCHSs.

Stress at work and at home has long been reported as the primary obstacle to successful quitting by AHWs. ${ }^{2,16}$ Research in other populations has shown that smoking for stress release is associated with relapse. ${ }^{17}$ However, successful quitting, for those who are able to do it, has been reported as being associated with reduced stress and, among Aboriginal people, with a general sense of pride and empowerment. ${ }^{18-20}$ Therefore, quitting smoking may reduce the stress these staff feel.

It does not appear, as previously reported, that a lack of quit support is a significant cause of relapse..$^{2,16}$ Many quit attempts by staff received additional support from the health service, and use of stop-smoking medications was higher among staff than among other Aboriginal and Torres Strait Islander smokers. High smoking prevalence among the Aboriginal and Torres Strait Islander community has previously been suggested as a cause of failed quit attempts. We found high numbers of smokers among the close friends and family of both staff and community smokers, which has also been associated with relapse in other settings. ${ }^{17}$

\section{Strengths and limitations}

This is the largest national survey on smoking among ACCHS staff. However, as with our sample of community members, it is not a random sample, with both using similar non-probabilistic quota sampling designs, so caution in interpreting results is required. The staff and other community members in our sample are from the same geographically representative locations, and comparisons are directly standardised to the distribution of the population of smokers in the NATSISS. We have elsewhere shown that the 1643 smokers in our community sample were similar to smokers in the NATSISS, except for some inconsistent socioeconomic differences. ${ }^{9}$
We can compare our sample with 224 organisations providing primary health care services for Aboriginal and Torres Strait Islander people in 2011-12. ${ }^{21}$ These organisations included, but were not restricted to, member ACCHSs of the National Aboriginal Community Controlled Health Organisation, and included more services from remote areas (39\%) and fewer from major cities (12\%) than in our study. ${ }^{9}$ Similar proportions of staff were reported to be Aboriginal and Torres Strait Islander (57\% of 5543 fulltime equivalent staff) and to be doctors $(6 \%)$ and nurses (14\%) as in our sample (58\%, $8 \%$ and $14 \%$, respectively). Based on these criteria, there was limited response bias in our sample.

Unlike most similar previous research, we have chosen to report on all Aboriginal and Torres Strait Islander ACCHS staff, not just AHWs, as all these staff are health role models in their communities, and the distinction between AHWs and other roles at the ACCHS can vary across the country.

Acknowledgements: The full list of acknowledgements is available in Appendix 3

Competing interests: No relevant disclosures.

Provenance: Not commissioned; externally peer reviewed.

Received 30 Oct 2014, accepted 27 Mar 2015.

1 Australian Bureau of Statistics. Australian Aboriginal and Torres Strait Islander Health Survey: updated results, Australia, 2012-13. Canberra: ABS, 2014. (ABS Cat. No. 4727.0.55.006.)

2 Mark A, McLeod I, Booker J, Ardler C. Aboriginal health worker smoking: a barrier to lower community smoking rates? Aboriginal Isl Health Wor J 2005; 29: 22-26.

3 Winstanley M (updated by van der Sterren A, Knoche D). Tobacco use among Aboriginal peoples and Torres Strait Islanders. In: Scollo MM, Winstanley MH, editors. Tobacco in Australia: facts and issues. 4th ed. Melbourne: Cancer Council Victoria, 2012. http://www. tobaccoinaustralia.org.au/chapter-8-aptsi (accessed Mar 2015).

4 Abdullah AS, Stillman FA, Yang L, et al. Tobacco use and smoking cessation practices among physicians in developing countries: a literature review (1987-2010). Int J Environ Res Public Health 2014; 11: 429-455.

5 Smith DR, Leggat PA. An international review of tobacco smoking in the medical profession: 1974-2004. BMC Public Health 2007; 7: 115.

6 Smith DR, Leggat PA. The historical decline of tobacco smoking among Australian physicians: 1964-1997. Tob Induc Dis 2008; 4: 13.
7 Davis RM. When doctors smoke. Tob Control 1993; 2: 187-188.

8 Chapman S. Falling prevalence of smoking: how low can we go? Tob Control 2007; 16: 145-147.

9 Thomas DP, Briggs VL, Couzos S, et al. Research methods of Talking About The Smokes: an International Tobacco Control Policy Evaluation Project study with Aboriginal and Torres Strait Islander Australians. Med J Aust 2015; 202 (10 Suppl): S5-S12.

10 Australian Bureau of Statistics. National Aboriginal and Torres Strait Islander Social Survey, 2008. Canberra: ABS, 2009. (ABS Cat. No. 4714.0.)

11 Thomas DP. Changes in smoking intensity among Aboriginal and Torres Strait Islander people, 1994-2008. Med J Aust 2012; 197: 503-506.

12 Maksimovic L, Paquet C, Daniel M, et al. Characterising the smoking status and quit smoking behaviour of aboriginal health workers in South Australia. Int J Environ Res Public Health 2013; 10: 7193-7206.

13 Tong EK, Strouse R, Hall J, Schroeder SA. National survey of US health professionals' smoking prevalence, cessation practices, and beliefs. Nicotine Tob Res 2010; 12: 724-733.

14 Thompson M, Robertson J, Clough A. A review of the barriers preventing Indigenous Health Workers delivering tobacco interventions to their communities. Aust N Z J Public Health 2011; 35: 47-53.

15 Dawson AP, Cargo M, Stewart H, et al. "I know it's bad for me and yet I do it": exploring the factors that perpetuate smoking in Aboriginal Health Workers - a qualitative study. BMC Health Serv Res 2012; 12: 102.

16 Dawson AP, Cargo M, Stewart H, et al. Aboriginal health workers experience multilevel barriers to quitting smoking: a qualitative study. Int J Equity Health 2012; 11: 27.

17 Herd N, Borland R, Hyland A. Predictors of smoking relapse by duration of abstinence: findings from the International Tobacco Control (ITC) Four Country Survey. Addiction 2009; 104: 2088-2099.

18 Chassin L, Presson CC, Sherman SJ, Kim K. Long-term psychological sequelae of smoking cessation and relapse. Health Psychol 2002; 21: 438-443.

19 McDermott MS, Marteau TM, Hollands GJ, et al. Change in anxiety following successful and unsuccessful attempts at smoking cessation: cohort study. Br J Psychiatry 2013; 202: 62-67.

20 Bond C, Brough M, Spurling G, Hayman N. "It had to be my choice" Indigenous smoking cessation and negotiations of risk, resistance and resilience. Health, Risk \& Society 2012; 14: 565-581.

21 Australian Institute of Health and Welfare. Aboriginal and Torres Strait Islander health services report 2011-12: online services report key results. Canberra: AlHW, 2013. (AlHW Cat. No. IHW 104.) 